\title{
Erratum to: The surgical management of chronic subdural hematoma
}

\author{
Andrew F. Ducruet ${ }^{1} \cdot$ Bartosz T. Grobelny $^{1} \cdot$ Brad E. Zacharia $^{1} \cdot$ Zachary L. Hickman $^{1}$ \\ Peter L. DeRosa ${ }^{1} \cdot$ Kristen N. Andersen $^{1} \cdot$ Eric Sussman $^{1}$ • Austin Carpenter ${ }^{1}$ • \\ E. Sander Connolly Jr. ${ }^{1}$
}

Published online: 3 July 2015

(C) Springer-Verlag Berlin Heidelberg 2015

Erratum to: Neurosurgical Review 35 (2): 155-169

DOI 10.1007/s10143-011-0349-y

The original version of this article contained a mistake in the name of one of the authors. Kristen Anderson should be presented as Kristen N. Andersen.

The online version of the original article can be found at http://dx.doi.org/ 10.1007/s10143-011-0349-y.

Andrew F. Ducruet

afd12@columbia.edu

1 Department of Neurological Surgery, College of Physicians \& Surgeons, Columbia University, 710 West 168th Street, New York, NY 10032, USA 